\title{
A Simple Investigation into the Stability of Lightweight Motorcycle
}

\author{
Chuthamat Laksanakit $^{1, \mathrm{a}, *}$, Pichai Taneerananoon ${ }^{2, \mathrm{~b}}$, and Kitti Wichettapong ${ }^{3, \mathrm{c}}$ \\ 1 Department of Civil Engineering, Faculty of Engineering, Prince of Songkla University Hatyai, Songkhla \\ 90110, Thailand \\ 2 Euro-Asia Road Safety Centre of Excellence, Department of Civil Engineering, Faculty of Engineering, \\ Prince of Songkla University Hatyai, Songkhla 90110, Thailand \\ 3 Department of Mechanical Engineering, Faculty of Engineering, Khon Kaen University, Khon Kaen \\ 40002, Thailand \\ E-mail: a chuthamat.1@rmutsv.ac.th (Corresponding author),b breathislife@yahoo.com,ckitwic@kku.ac.th
}

\begin{abstract}
The objective of this study is to investigate the stability of lightweight motorcycle in straight path running test. The stability of three different tyre dimensions was measured using acceleration, angular velocity and vehicle speed signals from smartphone sensors. The signals were analysed to determine whether standard configuration of tyres used in lightweight motorcycles in various developing countries are safe in terms of vehicle stability. In order to identify effects of tyre width on driving stability, forward speed, angular acceleration and rotational velocity were measured. These measurements are valuable empirical data in the understanding of motorcycle balance mechanism. Results of analysis show that for the range of tyre width $70 \mathrm{~mm}$ to $110 \mathrm{~mm}$ for the front and $80 \mathrm{~mm}$ to $120 \mathrm{~mm}$ for the rear wheel used in the test, motorcycle stability is not affected by the tyre width for the straight path run with maximum speed of $60 \mathrm{~km} / \mathrm{h}$.
\end{abstract}

Keywords: Motorcycle, stability, smartphone, motorcycle tyre width, straight running test.

ENGINEERING JOURNAL Volume 20 Issue 2

Received 22 July 2015

Accepted 26 October 2015

Published 18 May 2016

Online at http://www.engj.org/

DOI:10.4186/ej.2016.20.2.199 


\section{Introduction}

It is wildly acknowledged that road traffic accident is one of the leading cause of death worldwide. According to World Health Organization (WHO) [1, 2], Thailand as well as others SEA countries, uses a great number of motorcycles and is confronting with high rate of motorcycle user fatalities and injuries. It is well accepted that road traffic accidents or road crashes occur when at least one of the three elements: human errors, road and environment defects or vehicle defects comes into play; though these elements often form a chain of event leading to a crash. Various studies have been conducted on the causes and consequences of road crashes in ASEAN countries including Thailand. Huy et.al. used a new method for identifying black spots in Ho Chi Mihn city, based on potential for cost saving; the method has the potential to improve black spots which are the result of road and environmental defects and contributes to the improvement of safety for motorcycle users in Vietnam [3, 4]. Studies by Opas et al. highlighted the critical problem of several hundreds of annual roadside fatalities caused by the presence of trees within the clear zone of national highways in Thailand $[5,6]$. The effect of road element defects in the road crash's chain of event was also investigated in a highway flyover- improved intersection study, the study showed that while the flyover can improve safety at the intersection, but the high number of crashes occurred during the construction process needs to be addressed [7]. As regards motorcycle accidents which are the most pressing road crash challenge in Thailand, extensive efforts on law enforcement have been implemented, but in terms of engineering and education, more efforts are clearly needed. However, the numbers of motorcycle fatalities are still unacceptably high.

Recent statistics show that there have been large numbers of road deaths in Thailand, especially for motorcycle users. The Road Accident Victims Protection [8] gave details of the claims involving motorcycle users from 2011 to 2013 as shown in Fig. 1. The total numbers of injuries are unacceptably high at more than 200,000 per year. Fatality numbers were on average 7,400 cases per year or roughly 20 motorcyclists die on the road due to traffic accidents every day. These poor statistics, however, have to be considered taking into account a strong increase in the motorcycle fleet, with over 1 million units sold annually; the cumulative numbers are almost 20 million vehicles in 2012 [9] as shown in Fig. 2.

Motorcycles have been a popular mode of transportation. However, because of the vehicle structure, it is not as safe as other vehicles. They are not, in general, provided with protection features e.g. airbags, AntiLock Braking System (ABS) and traction control; this makes motorcycles less safe than other types of vehicle. Also, their stability can be a cause of much concern. The motorcycle stability directly depends on its dynamic characteristics (e.g. vehicle speed, lean angle and acceleration) and the static characteristics (e.g. vehicle geometry, mass distribution, frame compliance, suspension characteristics and tyre properties) [1012].

The vitality of these characteristics have been highlighted in previous studies. In his landmark study, [13] Kasantikul found that about one-eighth of motorcycle accidents in Bangkok were single-vehicle collisions; and the most frequent form of collisions was rear-ending another vehicle. In terms of vehicle factor, half of accidents involved 101 to $125 \mathrm{cc}$ engine capacity and OEM (original equipment manufacturer) tyres. These findings pose the question as to how much influence a tyre characteristics has on the stability of motorcycle (see Fig. 3). This is because the tyre is the only component of the motorcycle that transfers forces and moments between the vehicle and the road.

The main aim of this study is to investigate the stability of lightweight motorcycles using three different types of tyre, running on straight section, using forward speed, rotational angle, acceleration and angular velocity signals. The stability investigation involves an analysis of interaction signal generated when the motorcycle was running on straight section experiment, using data from GPS, 3-axis accelerometers and 3axis gyroscopes sensors which are incorporated in modern smartphones. The measurements recorded by a smartphone are valuable data which are essential for analyzing and understanding the influence of the tyre configuration on motorcycle stability. The initial findings of this study could provide information about driving stability and a number of relevant factors as well as tyre properties. 


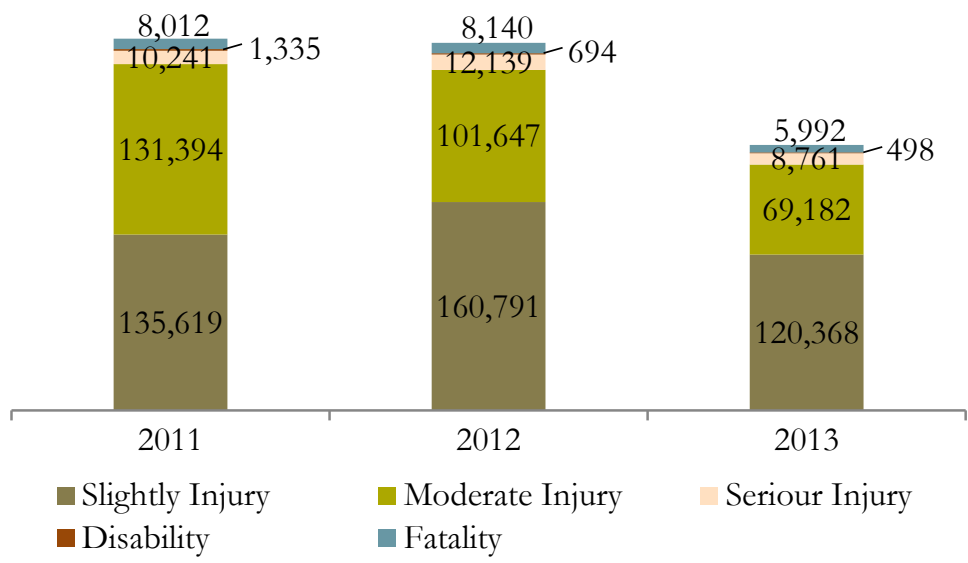

Fig. 1. Insurance claims involving motorcycle users [8].

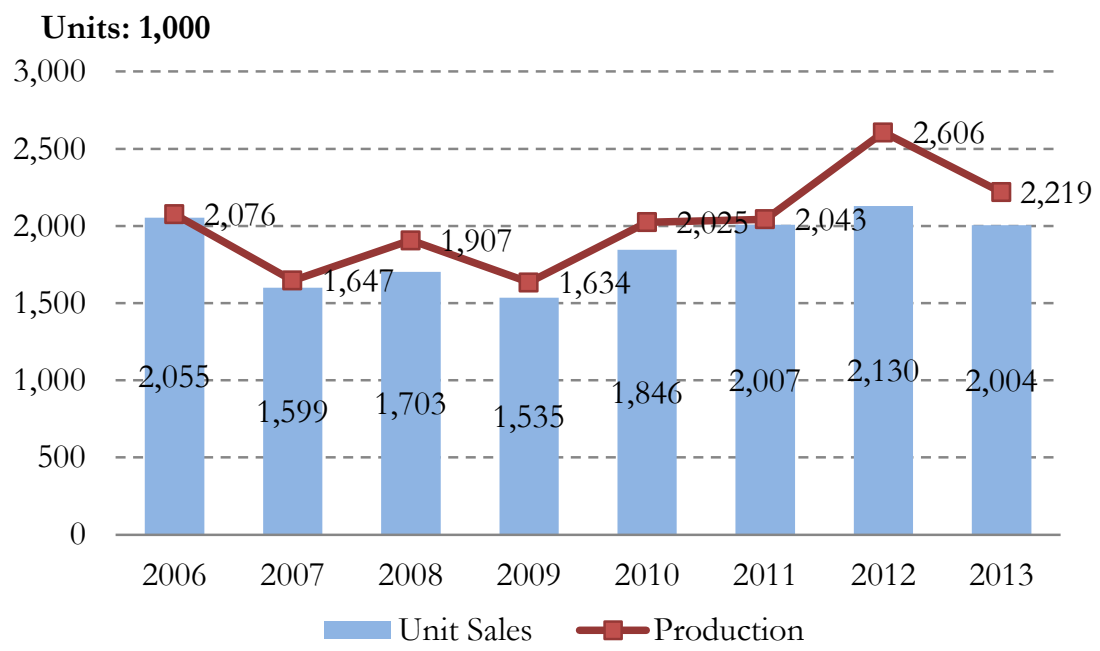

Fig. 2. Thailand motorcycle production and domestic sales [9].

Front

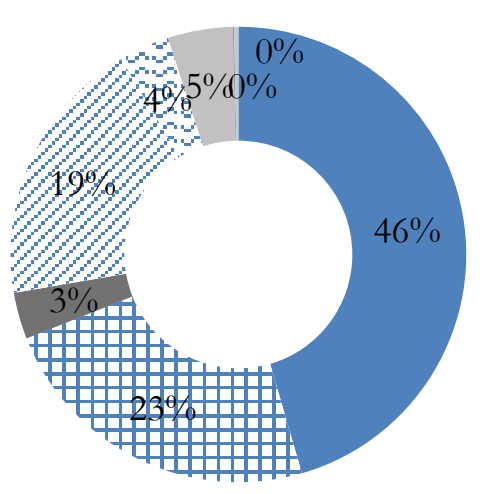

Rear

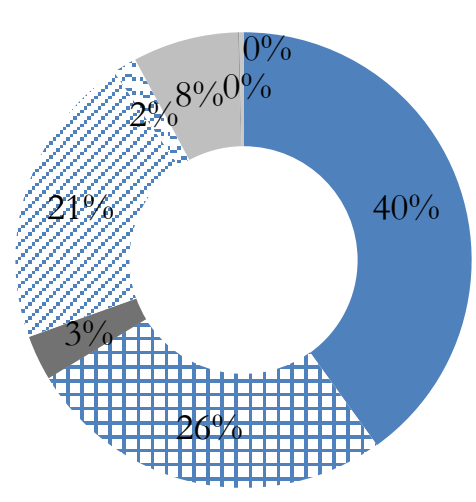

• Original equipment

+ Not original, but special size

n Proper rim size, over size section

Proper rim size, under size

section

$\approx$ Improper rim size, too large

- Improper rim size, too small

- Other

$\square$ Unknown

Fig. 3. Motorcycle tyre size involved in accidents [13]. 


\section{Previous Works}

Generally, stability of motorcycles is a major representation of motorcycle safety and studying this issue is considered a challenge. Dynamical behaviour of motorcycle riding can give rise to high instability due to the complexity of the system. Many related studies were carried out by researchers from developed countries including Italy, Germany and France where appropriate technology and budget are available. Transferring of the four-wheeled vehicles safety systems such as airbag, Electronic Stability Control (ESC), Anti-Lock Braking System (ABS), Traction Control System (TCS) and also airbag jacket systems to motorcycle has been emerging over the last decade. Unfortunately, in developing countries, including Thailand where the motorcycle users make up some 80 percent of road users, the issue of motorcycle stability receives little attention, while it should get the attention it deserves.

A number of important studies have been presented on motorcycle dynamics and control with regard to stability. Many previous studies have focused on stability under cornering condition by using simulation or modeling approach [14-16]. Recently attention was paid to the development of active control systems such as Advanced Rider Assistance Systems (ARAS) [17-20] Anti-Lock Braking System (ABS) and Traction Control Systems (TCS) using experimental approach [21]. The vehicles used in these studies were normally high performance motorcycles with engine capacity greater than $250 \mathrm{cc}$. Only a few studies including [22] have directly investigated lightweight motorcycle with engine capacity lower than $125 \mathrm{cc}$. It's worthwhile to look closely at this type of motorcycles as they are most common in developing countries.

As for motorcycle stability, the rider and the design of the machine have a deep influence on its dynamic stability both under driving and braking conditions. At very low speed, control of motorcycle directly depends on the ability of the rider to stabilize the vehicle by turning the handlebar. At higher speed, gyroscopic effects allow the motorcycle to follow a path and play an important role in balancing the vehicle [23]. From a theoretical point of view, stability of a motorcycle is defined by the fact that the available friction is higher than the lateral acceleration [11, 21]. In fact motorcycle tyres are the main component that generate friction between the road surface and the tyres and transfer the forces to the road surface. Instability phenomenon of the motorcycle can commonly result when the available friction is insufficient due to inadequate tyre properties or presence of surface liquid. In this study, only the tyre width factor is considered as it is a key component with regard to gaining better understanding of its impact on motorcycle stability.

Given the fact that an increase in motorcycle tyre width creates greater contact area, and therefore the larger tyre will have greater amount of tyre friction. By measuring the dynamic behvaiour of motorcycle using tyres with various tyre widths, it is possible to study the influence of tyre width on motorcycle driving stability. The dynamics stability parameters like angular rotation rate and angular acceleration are typically used to measure the direction and position in global axes (XYZ axes) at which particular motion of motorcycle occurs. The tyre width effect on driving stability could be principally quantified in terms of three dynamic stability parameters: roll angle (bank angle), pitch angle and yaw angle. These parameters were commonly used to identify dynamic instability conditions of motorcycle in previous works of $[14,19$, 24]. Roll angle (see Fig. 4) in particularly is a vital parameter with strong influence on the motorcycle stability. The degree of the angle normally depends on lateral acceleration and gravitational force of a motorcycle. To evaluate the level of stability of motorcycle, the hypothesis in the current study is based on the minimum range of the roll angle. This indicates that the combined Center of Mass of the rider and the motorcycle is in high-performance mode which enables the vehicle to be in upright position along a straight path.

\section{Methods}

\subsection{Instrumented Motorcycle}

SUZUKI Sky Drive with $125 \mathrm{cc}$. engine, as shown in Fig. 4, was selected for the straight running test. It was equipped with a Samsung Galaxy Note 3 smartphone. On board sensors of acceleration, gyroscope and GPS give measurement of accelerations, rate of motion and the positioning information. A DJI FC40 Wi-Fi camera was mounted on the motorcycle rider's jacket to capture the real-time riding information. All video recording is stored in a micro SD card. 
Smartphone is a probe device widely used for data recording. It has grown in popularity as an accurate measurement instrument because of its easy to use feature, inexpensive cost and reliable output. A number of recent studies using smartphone including the works of [25,26] on road roughness conditions and [27] which examined the possibility of realizing safe mobility of powered two-wheeler vehicle show that smartphones can give data with high accuracy in the frequency range of 40 to $50 \mathrm{~Hz}$.

The application named AndroSensor and Bubble Level 360 [28] were pre-installed into the smartphone. The AndroSensor was used to record key data such as 3-axis accelerations, 3-axis angular velocities, and vehicle speeds. The recording interval was done at $20 \mathrm{~Hz}$ frequency or 0.05 seconds. All information from the sensors was recorded into a CSV file. The box housing the smartphone was positioned on level plane under the rider seat as shown in Fig. 5. The application, Bubble Level 360 was used to accurately position the smartphone.

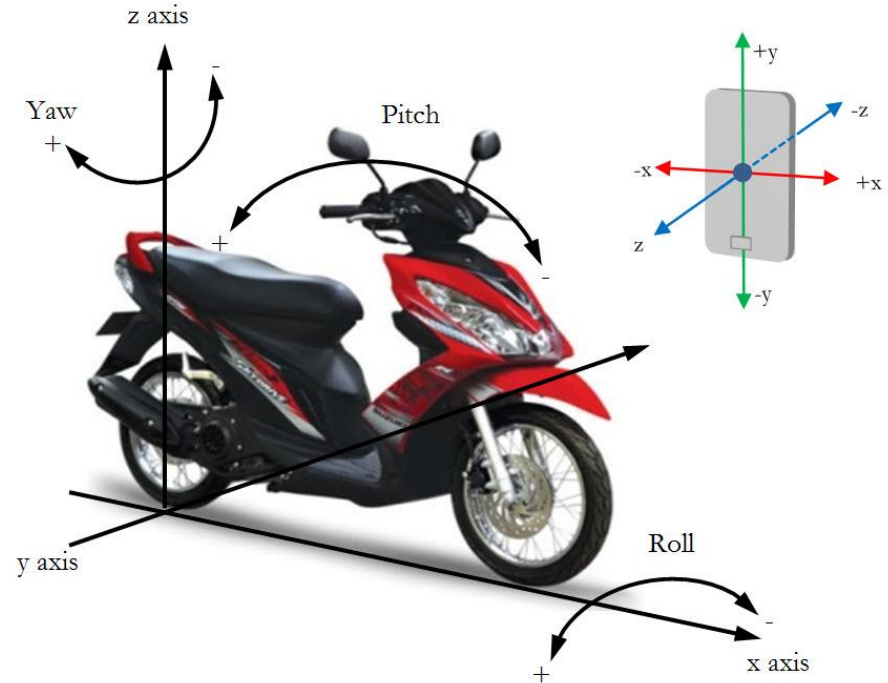

Fig. 4. SUZUKI Sky drive.

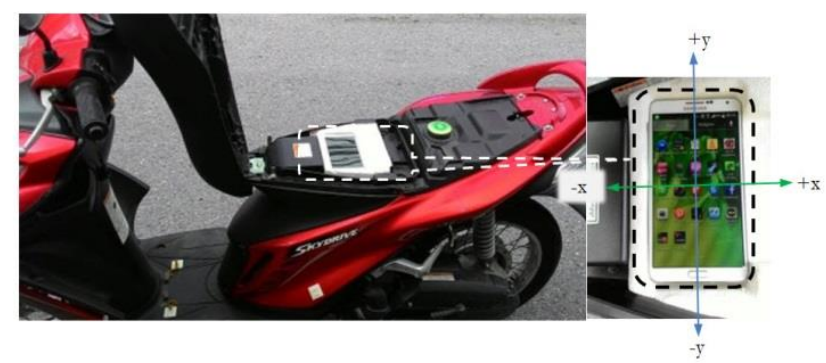

Fig. 5. View of the box fitted under the rider's seat.

Three different tyre characteristics were used for the test runs With respect to the standard configurations, the SUZUKI Sky drive has 14 inch spoke wheel rims with $70 \mathrm{~mm}$ tyre width/ 80 tyre height for the front wheel and $80 \mathrm{~mm}$ tyre width/ 90 tyre height for rear wheel, the configuration was designated as Tyre set A. Motorcycle with the same $90 \mathrm{~mm}$ tyre width/ 90 tyre height for both the front and rear wheels was designated as Tyre set $B$ and motorcycle with the front wheel of $110 \mathrm{~mm}$ width/ $70 \mathrm{~mm}$ height and the rear wheel $120 \mathrm{~mm}$ width/70 $\mathrm{mm}$ height as Tyre set C; details are as shown in Table 1 and Fig. 6 below.

\subsection{Straight Running Test Program}

The tests were performed on a highway with general grade within Songkhla municipality, Thailand. All straight running tests were conducted in clear weather condition and dry road surface. These allow efficient maneuverability and visibility riding. By using the same rider for each test, it is reasonable to assume that 
the riding behaviors would have minimal interference in the output. At the starting point, the rider was briefed on the path and the procedure. The test procedure required that the rider controlled the vehicle until the desired speed was attained and then took his hands off the handlebar in order to produce free rotation of the steering system. The rider stopped the vehicle at the end of the path or when oscillation amplitude approached an instability state. The data on travel speed, 3-axis acceleration, 3-axis angular velocity and GPS positions were recorded in the Smart Phone memory card.

The straight running test program was designed to investigate the dynamic behaviors of lightweight motorcycles in terms of the frequency of the principal vibration's mode out-of-plane (roll, pitch and yaw) [12]. A different set of speeds and tyre widths were changed to verify their impacts on the vehicle stability. Table 2 shows the straight running test program. For the lower test speeds $(30 \mathrm{~km} / \mathrm{h}, 40 \mathrm{~km} / \mathrm{h})$ and the higher test speeds $(50 \mathrm{~km} / \mathrm{h}$ and $60 \mathrm{~km} / \mathrm{h}$ ) the instrumented motorcycle was tested with ten replications each. The front and rear tyre inflation pressures for all tyres were fixed in order to control their influence.

\section{Data Analysis}

The measurement of 3-axis accelerations, 3-axis angular velocities and forward speed for each task were recorded from the straight line motion of the motorcycle where the $\mathrm{x}$-axis is rotated along the longitudinal axis of the motorbike, the y-axis is aligned perpendicularity to forward movement direction and the $z$-axis is the vertical motion. In each measurement data were determined from the logged data and synchronized. The data of motion characteristics were extracted, based on the free motion of steering system for constant forward speed duration. The filtered data were double-checked from the recorded video.

In order to better understand how the vibration amplitude or waveform of the roll, pitch and yaw rate occurred over the time domain, the following investigation was carried out. Considering motorcycle geometric features as shown in Fig. 4, the equilibrium $\mathrm{x}$ axis displays the longitudinal direction, the $\mathrm{y}$ axis defines the lateral direction and the $\mathrm{z}$ axis, the vertical direction or the perpendicular direction to the $\mathrm{xy}$ plane. To detect motorcycle response frequency in terms of roll rate, the $\mathrm{x}$ axis direction must correspond with the $\mathrm{x}$ ' axis direction of smartphone (see Figs. 4 and 5). When the test motorcycle leans to the left hand side (LHS) of the rider, the roll rate gives a reading of negative number, likewise if it leans to the right hand side (RHS) a positive reading would be detected. This coordinate system condition was similarly defined for the other two directions $y$ and $z$ axis. A positive reading of pitch rate along the $y$-axis would be recorded when the front wheel rises in relation to the rear wheel or the motorcycle pitches rearwards whereas a negative reading would signify pitching motion in opposite direction. The $z$ axis defines an orientation of motorcycle with respect to vertical direction; a positive reading signifies counter clockwise motion of the motorcycle while clockwise motion would give negative value.

Data were analysed using manufacturer software. The roll angle was calculated and chosen as the stability index in this study because the stability state of motorcycle along the longitudinal axis has greatest influence on the vehicle stability when travelling in straight direction. This is because the motorcycle tends to easily fall over sideway, while the front and the rear wheel could provide supports for the motorcycle body in y-axis and $z$-axis [23].

As for the signal, the waveform of vibration response signals of the 3-axis angular velocities or 3-axis accelerations were normally considered. The waveform is a graph of response signal versus selected time series period. The magnitude or frequency of measured signal was evaluated by considering the magnitude of peak level, peak to peak, average and root mean square. In this study the average of measured signal was selected because this method was simple and efficient [24].

Table 1. Experiment arrangement.

\begin{tabular}{cccc}
\hline & Front Wheel & Rear Wheel & Remark \\
\hline Tyre set A & $70 / 80-14 \mathrm{M} / \mathrm{C}$ 34P & $80 / 90-14 \mathrm{M} / \mathrm{C}$ 40P & *Standard Configuration \\
Tyre set B & $90 / 90-14 \mathrm{M} / \mathrm{C}$ 46P & $90 / 90-14 \mathrm{M} / \mathrm{C}$ 46P & \\
Tyre set C & $110 / 70-14 \mathrm{M} / \mathrm{C} \mathrm{56P}$ & $120 / 70-14 \mathrm{M} / \mathrm{C} \mathrm{61 \textrm {P }}$ & \\
\hline
\end{tabular}


Table 2. Straight running test programs.

\begin{tabular}{cccc}
\hline Test run & Tyre set & $\begin{array}{c}\text { Speed } \\
(\mathrm{km} / \mathrm{h})\end{array}$ & Number of Replications \\
\hline 1 & $\mathrm{~A}$ & 30 & 10 \\
2 & & 40 & 10 \\
3 & & 50 & 10 \\
4 & $\mathrm{~B}$ & 60 & 10 \\
\hline 5 & & 30 & 10 \\
6 & & 40 & 10 \\
7 & $\mathrm{C}$ & 50 & 10 \\
8 & & 60 & 10 \\
\hline 9 & & 30 & 10 \\
10 & & 40 & 10 \\
11 & 50 & 10 \\
12 & & 60 & 10 \\
\hline
\end{tabular}

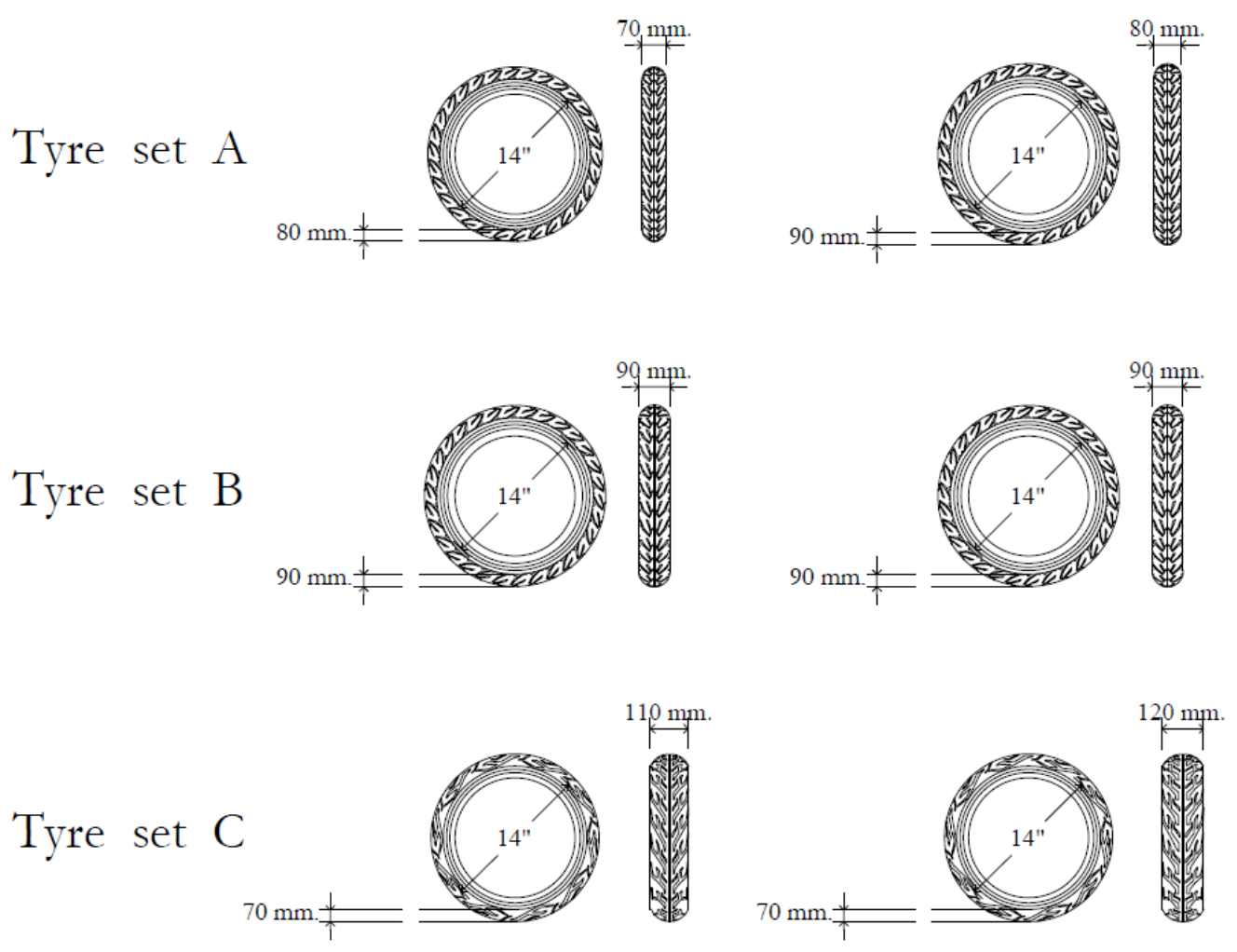

Fig. 6. Tyre dimensions.

\section{Results}

To identify the stability state of a motorcycle, the frequency of out-of-plane mode such as roll rate, pitch rate and yaw rate were principally considered $[14,19,24,29]$. Figures $7,8,9$ and 10 show examples of the raw vibration signal in terms of the experimental time histories of the roll, pitch and yaw rate of Tyre set $A$, Tyre set B and Tyre set C, respectively. These graphs are presented in waveform which are the measured signal of velocity (roll, pitch and yaw) versus real time signal (time history). From the graphs, it can be seen that a significant oscillation of roll rate (the thick line) shows high amplitude values, while pitch and yaw rates show smaller amplitude values. These figures clearly illustrate that for all experiments the motorcycle 
was able to control its out-of-plane vibrations and return back to its equilibrium position. Among the three different tyres, the frequency of roll rate of Tyre set $C$ was quite different in comparison to that of Tyre set $\mathrm{A}$ and $\mathrm{B}$, as indicated by its higher frequency. Moreover, the pitch and yaw rate oscillation seem to settle at lower frequency and amplitude. Similar performances are observed in the experiment at higher speed of 60 $\mathrm{km} / \mathrm{h}$.

In order to compare the stability of these three tyre configurations: Tyre set A, B and C; statistical techniques were applied to probe the dynamic response signal. An average of the roll angle of Tyre set A, Tyre set $B$ and Tyre set $C$ is shown in Figure 11. From the results, it is seen that the fluctuating motion of the motorcycle along the $\mathrm{X}-1$ that of longitudinal axis for Tyre set $\mathrm{A}$ is quite small with respect to zero axis than that of Tyre set B and less than that of the Tyre set C. These imply that, the stability of the motorcycle under the three different tyres in straight running tests is not affected by the tyre width. In other words, the tyre width does not cause any significant stability issue for light weight motorcycle at speed lower than 60 $\mathrm{km} / \mathrm{h}$.

Furthermore, the tyre properties in Table 3 show that tyres with different tyre width also have different radii and therefore differ in moment of inertia about the wheel axis. The fact that there was no significant impact of motorcycle tyre width on the vehicle stability under the straight running test condition could probably be due to an experiment constraint in that the same 14 inch wheel was being used in the experiment. This issue will be further investigated.
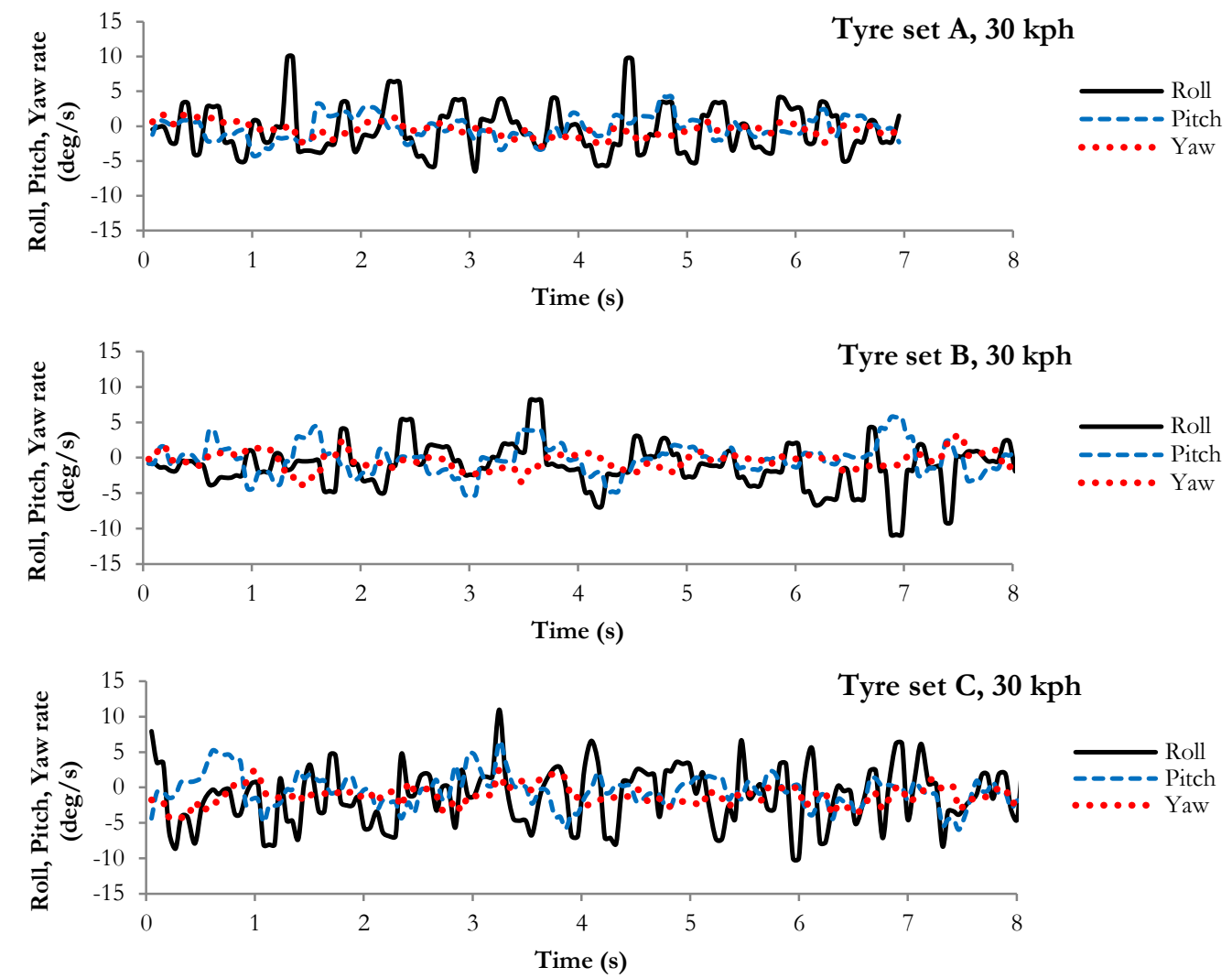

Fig. 7. Time history of roll, pitch and yaw rate of three different tyres at speed $30 \mathrm{~km} / \mathrm{h}$. 

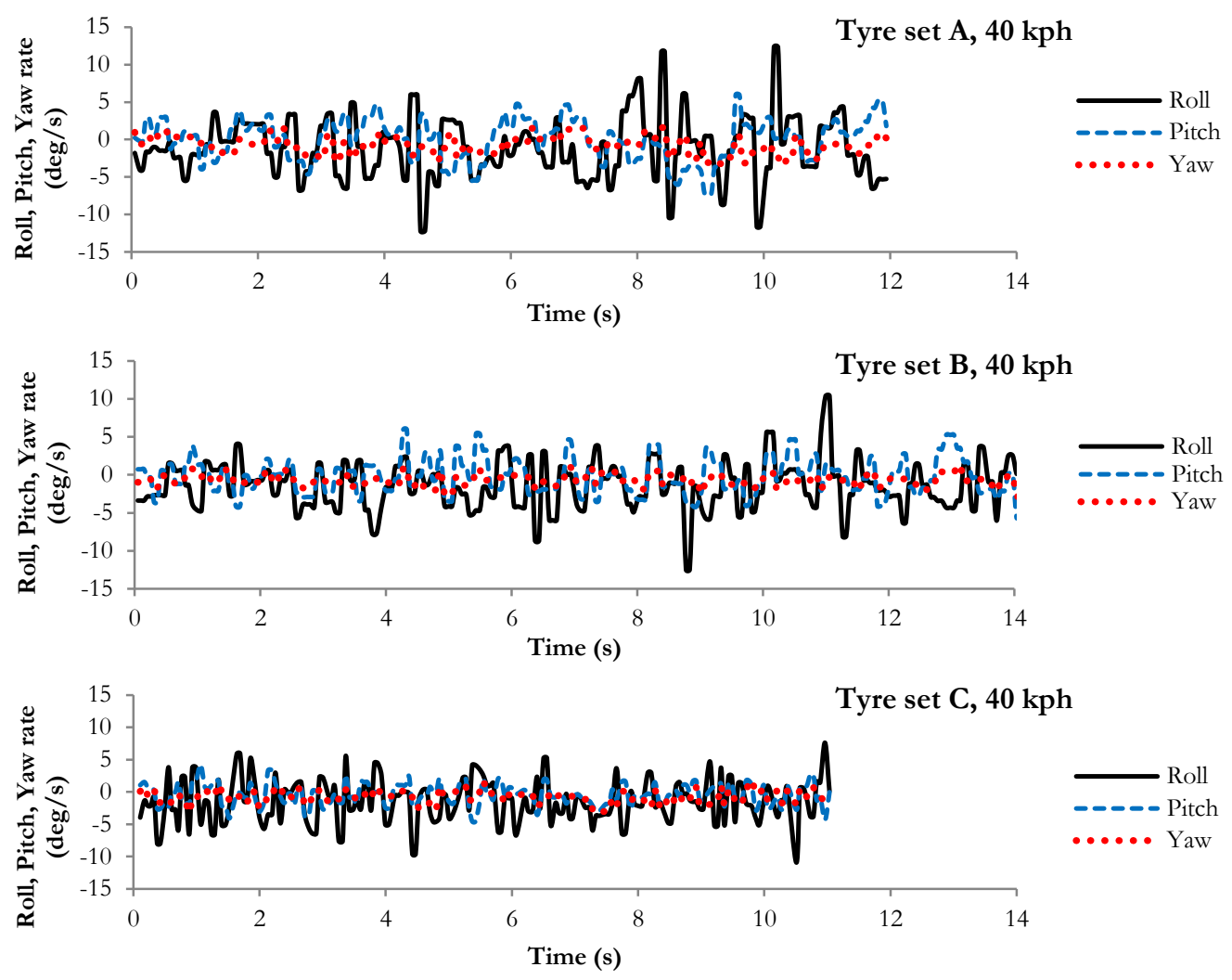

Fig. 8. Time history of roll, pitch and yaw rate of three different tyres at speed $40 \mathrm{~km} / \mathrm{h}$.
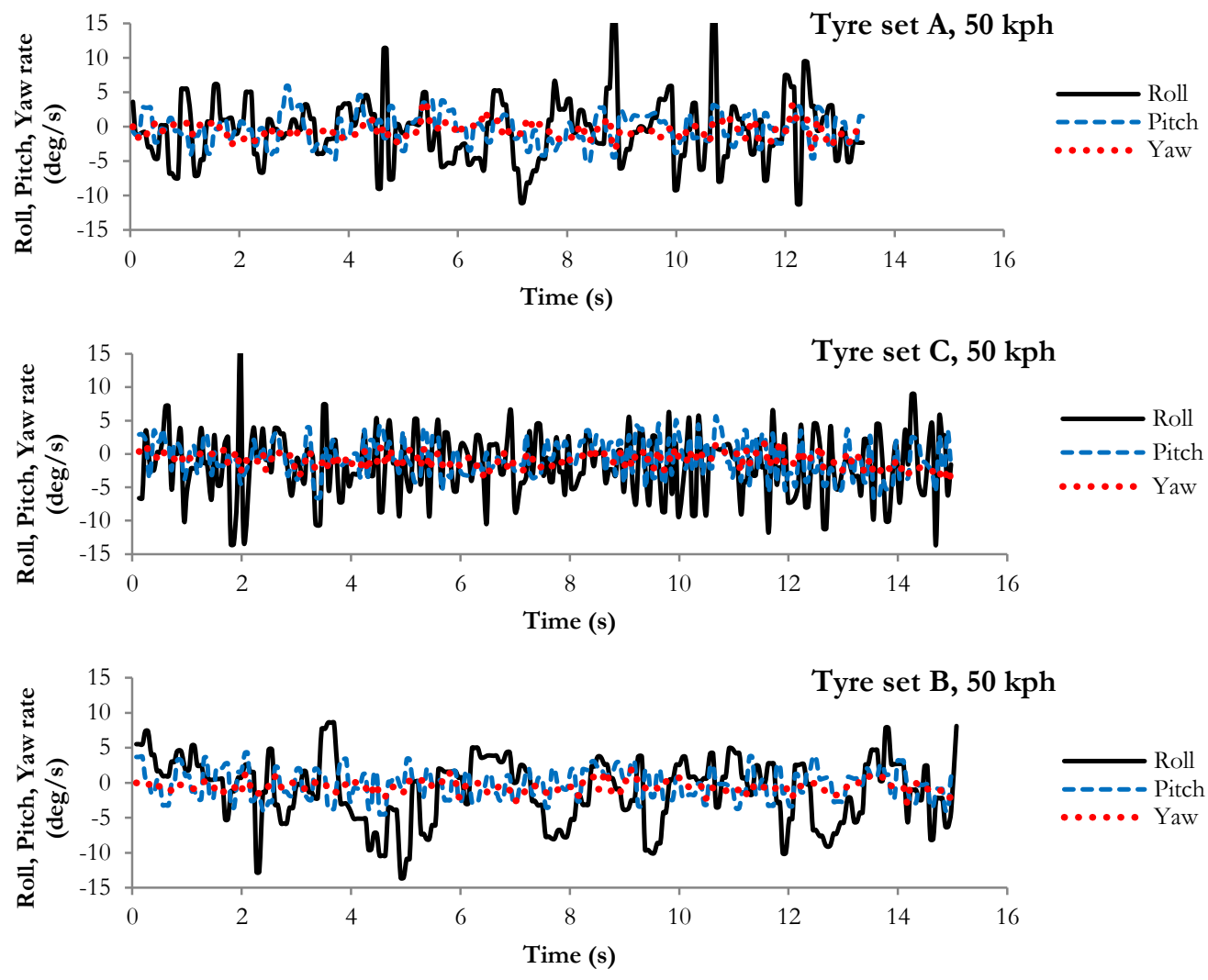

Fig. 9. Time history of roll, pitch and yaw rate of three different tyres at speed $50 \mathrm{~km} / \mathrm{h}$. 

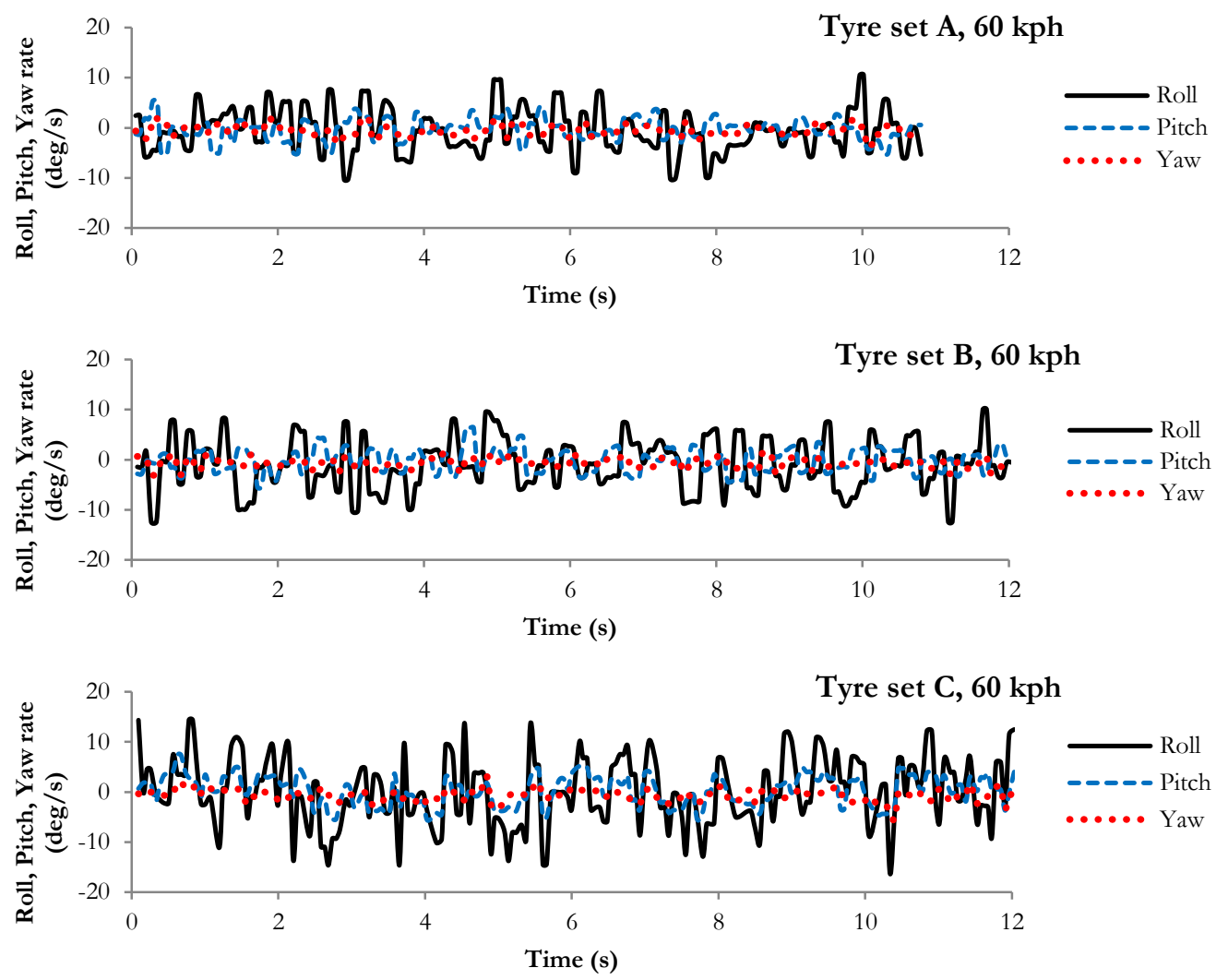

Fig. 10. Time history of roll, pitch and yaw rate of three different tyres at speed $60 \mathrm{~km} / \mathrm{h}$.

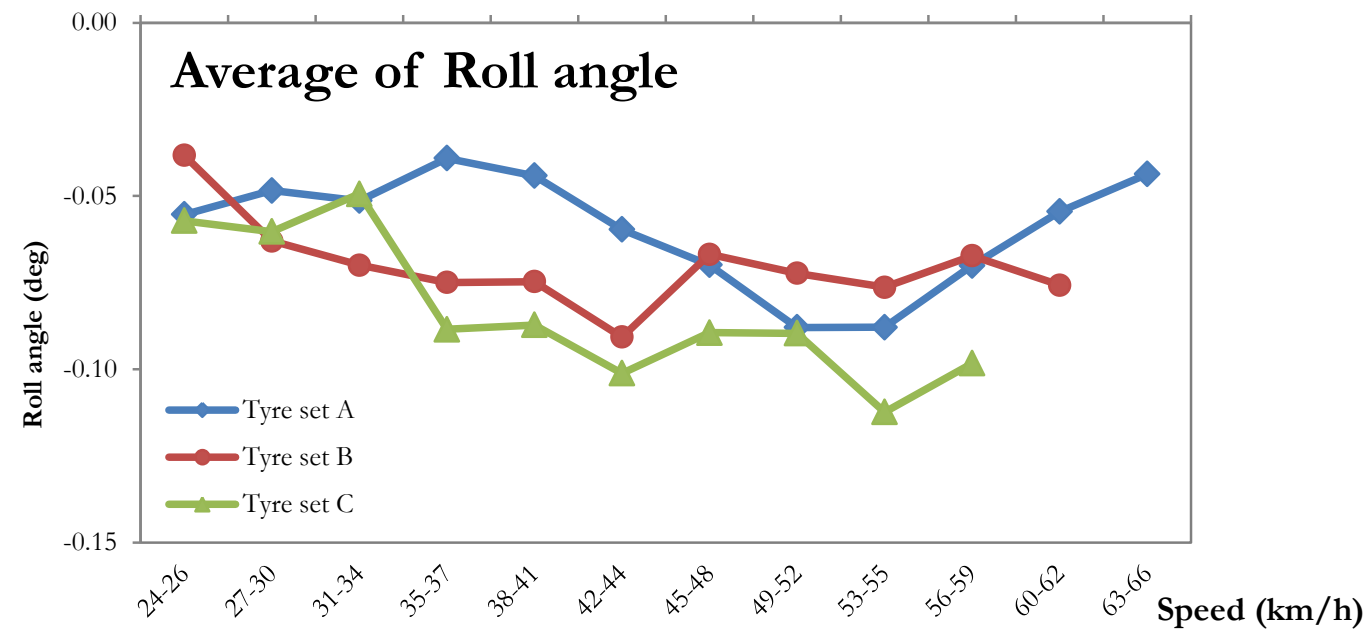

Fig. 11. Comparison of average of roll angle. 
Table 3. Tyre properties.

\begin{tabular}{ccccccc}
\hline & & Description & $\begin{array}{c}\text { Inflated tyre } \\
\text { pressure } \\
(\mathrm{psi})\end{array}$ & $\begin{array}{c}\text { Weight } \\
(\mathrm{kg})\end{array}$ & $\begin{array}{c}\text { Radius } \\
(\mathrm{m})\end{array}$ & $\begin{array}{c}\text { Moment of inertia } \\
\text { about wheel axis } \\
\left(\mathrm{kg} \times \mathrm{m}^{2}\right)\end{array}$ \\
\hline \multirow{2}{*}{ Tyre set A } & Front & $70 / 80-14 \mathrm{M} / \mathrm{C} \mathrm{34P}$ & 30 & 5.5 & 0.2403 & 0.3200 \\
& Rear & $80 / 90-14 \mathrm{M} / \mathrm{C} \mathrm{40P}$ & 32 & 6.7 & 0.2475 & 0.4095 \\
\hline \multirow{2}{*}{ Tyre set B } & Front & $90 / 90-14 \mathrm{M} / \mathrm{C}$ 46P & 30 & 6.4 & 0.2583 & 0.4255 \\
& Rear & $90 / 90-14 \mathrm{M} / \mathrm{C} \mathrm{46P}$ & 32 & 7.1 & 0.2598 & 0.4787 \\
\hline \multirow{2}{*}{ Tyre set C } & Front & $110 / 70-14 \mathrm{M} / \mathrm{C} \mathrm{56P}$ & 30 & 6.9 & 0.2564 & 0.4540 \\
& Rear & $120 / 70-14 \mathrm{M} / \mathrm{C} \mathrm{61P}$ & 32 & 8.0 & 0.2634 & 0.5550 \\
\hline
\end{tabular}

\section{Conclusion}

In this paper, a simple experiment of straight running test has been presented to study the stability of lightweight motorcycle by using a smart phone. The smart phone which has built- in sensors, and with freely available applications proves to be a low cost and effective measuring device. The findings from the straight running test at the maximum speed of $60 \mathrm{~km} / \mathrm{h}$ show that for up to this speed, the size of tyre used on these small light weight motorcycles has minimal effect on the vehicle's driving stability. The results of the study show that no differences in motorcycle stability on straight motion with longitudinal speed lower than $60 \mathrm{~km} / \mathrm{h}$ when the tyre width is in the 70 to $120 \mathrm{~mm}$ range.

\section{Acknowledgements}

This research was financially supported by the Prince of Songkla Graduate Studies Grant. The authors would like to thank THAI SUZUKI MOTOR Co.Ltd. (Thailand) for their generous support of two motorcycles for the study (SUZUKI Sky Drive). The authors are grateful to the professional riding instructor of the Disaster Prevention and Mitigation Center 12 Songkhla for his kind help in providing skillful riding for the tests.

\section{References}

[1] World Health Organization, "Global status report on road safety 2013: Supporting a decade of action," Luxembourg, 2013.

[2] M. Sivak and B. Schoettle, "Mortality from road crashes in 193 countries: A comparison with other leading causes of death," UMTRI-2014-6, Michigan, 2014.

[3] H. H. Nguyen, P. Taneerananon, C. Koren, and P. Luathep, "The evolution of criteria for identifying blackspots and recommendations for developing countries," Journal of Society for Transportation and Traffic Studies (JSTS), vol. 5, no. 3, pp. 16-28, 2014.

[4] H. H. Nguyen and P. Taneerananon, "Approach to identifying black spots based on potential saving in accident costs," Engineering Journal, to be published.

[5] O. Somchainuek, P. Taneerananon, and S. Jaritngam, "An in-depth investigation of roadside crashes on Thai National Highways," Engineering Journal, vol. 17, no. 2, pp. 63-74, 2012.

[6] O. Somchainuek, S. Mama, P. Luathep, and P. Taneerananon, "Preventable deaths from roadside crashes in THAILAND: Is it time for action?," Journal of Society for Transportation and Traffic Studies (JSTS), vol. 4, no. 2, 2013.

[7] N. Salatoom and P. Taneerananon, "A study of flyover-bridge-improved intersection," Engineering Journal, vol. 19, no. 1, pp. 1-12, 2015.

[8] Road Accident Victims Protection Report (in Thai), 2013.

[9] ASEAN Automotive Federation Statistics. (2014). ASEAN Automotive Federation Statistics. [Online]. Available: http://www.asean-autofed.com/statistics.html [Accessed 5 May 2014].

[10] V. Cossalter, A. Doria , R. Basso, and D. Fabris, "Experimental analysis of out-of-plane structural vibrations of two-whelled vehicles," Shock and Vibration, vol. 11, pp. 433-443, 2004.

[11] V. Cossalter, Motorycle Dynamics. Lulu.com, 2006. 
[12] V. Cossalter, D. F. Doria, and M. Maso, "Measurement and identification of vibration characteristics of motorcycle riders," in Proc. ISMA 2006, leuven, 2006.

[13] V. Kasantikul, Motorcycle Accident Causation and Identification of Countermeasures in Thailand, vol. I: Bangkok Study. Bangkok: KP Printing, 2001.

[14] M. Ghosh and S. Mukhopadhyay, "Stability analysis of two-wheeler during curve negotiation under braking," in Proc. The 14th National Conference on Macbines and Mechanisms (NaCoMM09), Durgapur, 2009.

[15] H. Slimi, H. Arioui, L. Nouveliere, and S. Mammar, "Motorcycle speed profile in cornering situation," in Proc. The American Control Conference (ACC), MD, 2010, pp. 1172-1177.

[16] L. Nehaoua, D. Ichalal, H. Arioui, S. Mammar, and L. Fridman, "Lean and steering motorcycle dynamics reconstruction: An unknown input HOSMO approach," in Proc. The American Control Conference (ACC 2013), Washington, 2013

[17] F. Biral, P. Bostti and R. Lot, "Experimental evaluation of a system for assisting motorcyclists to safety ride road bend," European Transport Research Review, vol. 6, pp. 411-423, 2014.

[18] A. Boubezeoul, S. Espie, B. Larnudie, and S. Bouazziz, "A simple fall dection algorithm for powered two wheelers," Control Engineering Practice, vol. 21, pp. 286-297, 2013.

[19] F. Cheli, M. Pezzola, E. Leo, T. Ibrahim, and A. Saita, "Motorcycle dynamic stability monitoring during standard riding conditions," in Proc. Bycycle and Motorcycle Dynamic 2010, Delft, 2010.

[20] I. Boniolo, M. Norgia , M. Tanelli, C. Svelto, and S. M. Savaresi, "Performance analysis of an optical distance sensor for roll angle estimation in sport motorcycle," in Proc. The 17th World Congress The International Federation of Automatic Control, Seoul , 2008.

[21] P. Seiniger, K. Schroter, and J. Gail, "Perspectives for motorcycle stability control systems," Accident Analysis and Prevention, vol. 44, no. 6, pp. 74-81, 2012.

[22] C. W. Yuen, M. R. Karim, and A. Saifuzul, "Investigation on motorcyclist riding behaviour at curve entry using instrumented motorcycle," The Scientific World Journal, pp. 1-9, 2014.

[23] G. Cocco, Motorycle Design and Technology. Vimodrone: Giorgio Nada Editore, 2013.

[24] N. Jamieson, W. Frith, T. Lester, and V. Dravitzki, "Stability of motorcycles on audio tactile profiled (ATP) roadmarkings," Wellington, 2013.

[25] V. Douangphachanh and H. Oneyama, "A Study on the use of smartphones for road roughness condition estimation," in The Eastern Asia Society for Transportation Studies, Surabaya, 2013.

[26] V. Douangphachanh and H. Oneyama, "A study on the use of smartphone under realistic settings to estimate road roughness condition," EURASIP Journal on Wireless Communications and Networking, vol. 1, no. 114, pp. 1-11, 2014.

[27] T. Sekine, "Utilization of probe powered two-wheeler vehicles to realize a safe mobile society," LATSS Research, vol. 38, no. 1, pp. 58-70, 2014.

[28] Google Play. (2014). Bubble Level. [Online]. Available: https://play.google.com/store/apps/details?id=net. androgames.level\&hl=th [Accessed: Octorber 6, 2014].

[29] U. Nenner, R. Linker, and P.-O. Gutman, "Robust stabilization of an unmanned motorcycle," in 2008 IEEE International Conference on Robotics Automation and Mechatronics, Chengdu, 2008. 